\title{
periferio
}

\section{EDUCAÇÃO, SAÚDE E INCLUSÃO: CONHECENDO AS HISTÓRIAS DE VIDAS DE PESSOAS COM FEBRE REUMÁTICA ${ }^{1}$}

\author{
Fabiana Ferreira do Nascimento ${ }^{2}$ \\ SME Duque de Caxias-RJ \\ Melissa Cavalcanti Yaakoub ${ }^{3}$ \\ Instituto Nacional de Cardiologia \\ Celeste Maria Aquino ${ }^{4}$ \\ Instituto Nacional de Cardiologia
}

\section{Resumo}

Nesta investigação buscamos refletir sobre as relações acerca da educação e da saúde do sujeito com cardiopatia reumática atendido pelo Instituto Nacional de Cardiologia. 0 objetivo geral foi identificar as problemáticas ocasionadas pelo processo de adoecimento, mais especificamente, sobre o acesso à educação e a trajetória escolar desses sujeitos frente a esse evento. Dentre os referenciais teóricos, destacamos Muller (2011), que nos esclarece quem é a pessoa com febre reumática, Lima (2015), que disserta sobre a história de luta pela inclusão, principalmente de sujeitos com deficiência e doenças crônicas; e Glat e Blanco (2007) que ressaltam que a própria deficiência era vista como uma doença crônica, daí talvez a dificuldade do atendimento educacional em outros espaços além da escola. A metodologia está fundamentada nos pressupostos qualitativos de cunho exploratório e descritivo, compostas pelas narrativas de histórias de vida desses pacientes. A investigação aponta que os entrevistados possuem um histórico de reprovações e mencionam terem se afastado da escola por conta do longo e doloroso tratamento. Esperamos ao final dessa investigação contribuir para a reflexão sobre a situação de inclusão social, a partir de uma perspectiva de exclusão relatada pelos mesmos, frente aos direitos que deveriam ser

\footnotetext{
1 Essa investigação contou ainda com a colaboração da médica Dra. Regina Elizabeth Muller e da assistente social Dra. Aline Souto Maior, ambas profissionais do Instituto Nacional de Cardiologia/Ministério da Saúde/Rio de Janeiro/Brasil.

${ }^{2}$ Mestre em Ensino da Educação Básica/UERJ, Especialista em Saúde Pública/ENSP/FIOCRUZ, Professora do I Segmento do Ensino Fundamental - SME/Duque de Caxias-RJ. fabifnascimento@yahoo.com.br

3 Mestre em Política Social/UFF, Assistente social do Instituto Nacional de Cardiologia/Ministério da Saúde/Rio de Janeiro. melyaakoub@gmail.com

4 Especialista em Psicologia Hospitalar/CFP e Especialista em Saúde Mental Infantojuvenil/PUC-RJ, Psicóloga da Coordenação de Ensino e Pesquisa do Instituto Nacional de Cardiologia/Ministério da Saúde/Rio de Janeiro. celesteaquino@globo.com
} 


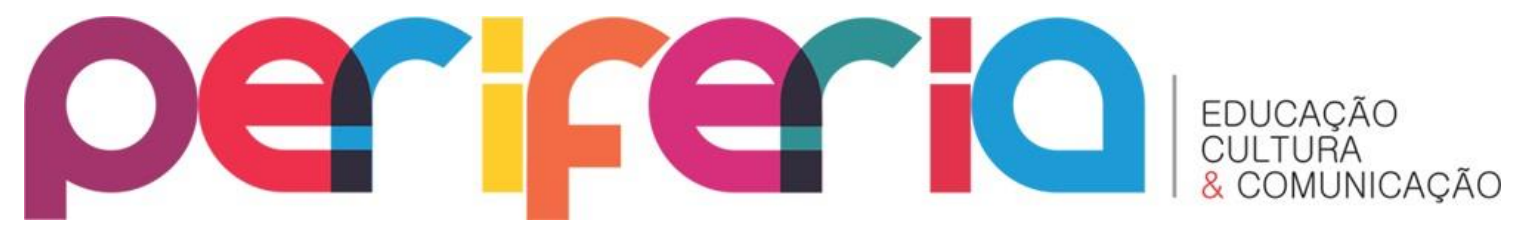

assegurados independente do adoecimento e período de tratamento/internação. Buscamos aqui evidenciar a necessidade de garantirmos a crianças e adolescentes que passam por essa problemática, condições necessárias; para a continuidade de seus estudos.

Palavras-chave: educação especial; inclusão; educação e saúde; doenças crônicas; febre reumática 


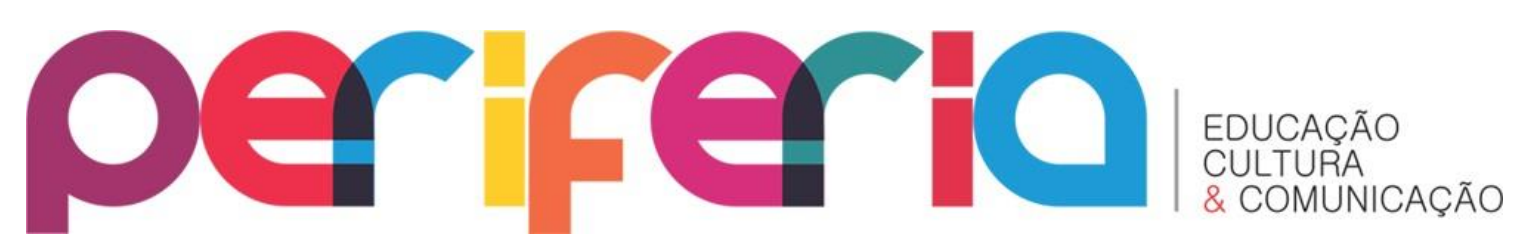

\author{
EDUCATION, HEALTH AND INCLUSION: KNOWING \\ THE LIFE HISTORIES OF PEOPLE WITH RHEUMATIC FEVER
}

\title{
Abstract
}

This research intended to reflect on the relationship between the education and the health of the subject with rheumatic heart disease followed up by the National Institute of Cardiology (Instituto Nacional de Cardiologia). The general objective was to identify the problems caused by the illness process, but specifically, about the access to education and the school life of these individuals forward to this event. Among the theoretical references, we highlight Muller (2011) who clarifies who is the person with rheumatic fever, Lima (2015) that highlights the history of struggle for the inclusion mainly of subjects with disabilities and chronic diseases; and Glat and Blanco (2007), who emphasize that disability itself was seen as a chronic illness, hence the difficulty of educational care in other spaces besides school. The methodology is based on the qualitative assumptions of an exploratory and descriptive nature, composed by narratives of life histories of these patients. The research indicates that the interviewees report about school failures and mention that they have withdrawn from school because of the long and painful treatment. We hope at the end of this research to contribute to the reflection on the social inclusion situation, from a perspective of exclusion reported by them, regarding the rights that should be ensured regardless of illness and period of treatment / hospitalization. We seek to highlight the need to guarantee children and adolescents who go through this problem, necessary conditions for the continuity of their studies.

Keywords: special education; inclusion; education and health; chronic diseases; rheumatic fever 


\section{periferio}

\section{CONHECENDO O QUE É A FEBRE REUMÁTICA}

A febre reumática $(F R)$ é uma doença inflamatória que ocorre, após uma infecção na garganta causada pela bactéria Estreptococo, tratada de forma inadequada em sujeitos geneticamente predispostos (MULLER, 2011).

A FR pode acometer, de maneira conjunta ou separada, as articulações (principalmente os cotovelos, punhos e joelhos), o cérebro, e especialmente o coração, deixando sequelas graves por toda a vida, que podem levar o paciente inclusive à morte (NASCIMENTO; CAETANO; MULLER et al., 2009).

A doença ocorre de maneira recidivante, isto quer dizer que, sempre que o sujeito tiver contato com a bactéria, na ausência de uma prevenção adequada e tratamento correto da infecção de garganta, aumentam os riscos de as lesões cardíacas irem se agravando.

A cardiopatia reumática $(C R)$, é uma complicação da FR e continua sendo ainda a principal causa de cardiopatia adquirida na infância e adolescência em todo o mundo (WHO, 2004). Estimativas da Organização Mundial da Saúde (OMS) em 2005 apontavam para cerca de 15,6 milhões de pacientes portadores de CR, e contabilizava um total de 233.000 mortes por ano diretamente atribuível à CR no mundo (CARAPETIS; STEER; MULHOLLAND et al., 2005).

A FR acaba atingindo um número bastante expressivo de crianças e adolescentes em idade escolar (geralmente dos 3 aos 15 anos); exigindo com frequência o acompanhamento do médico responsável, exames e consultas periódicas, e não raro, intervenções cirúrgicas e/ou internações prolongadas. Essas cirurgias têm como finalidade a reconstrução da válvula adoecida (plástica valvar), ou a troca dessa válvula doente por uma prótese. 0 que ocorre é que com o crescimento faz-se necessário nova troca da prótese ainda na infância, adolescência e/ou início da fase adulta (MULLER, 2011).

No Brasil, através dos dados do sistema DATASUS, verifica-se que no período de 2005 a 2007 foram registradas 23.482 internações e 29.126 cirurgias das válvulas cardíacas devido a CR (MULLER, 2011). 


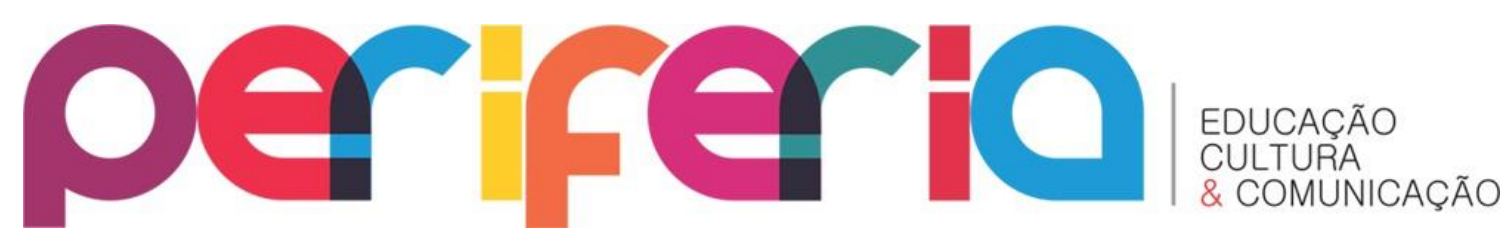

Para prevenir a doença, o tratamento das infecções de garganta deve ser feito com antibióticos, de preferência, com a aplicação de penicilina benzatina (primeira escolha). Mas, quando a doença já está instalada, para evitar a piora das lesões cardíacas, há a necessidade da aplicação desse medicamento (popularmente conhecido como "Benzetacil”), de 21 em 21 dias (profilaxia secundária) por muitos anos.

É uma enfermidade séria e seu tratamento é considerado de difícil adesão. Além disso, seu tratamento é longo e muito doloroso, o que pode acabar favorecendo o distanciamento do paciente de suas atividades cotidianas e sociais, mais especificamente, o acesso à educação e/ou a frequência escolar, foco desta investigação.

No entanto, é importante ressaltarmos, que o prognóstico do paciente com CR pode ser muito favorável em 65 a 75\% dos pacientes, se o tratamento for seguido corretamente. Esses casos acabam evoluindo sem complicações futuras e, consequentemente, sem o abandono de sua rotina de vida (MULLER, 2011).

É importante ainda dizermos que, quando analisamos o impacto social e econômico adicional, ou seja, os custos indiretos, como o nível de repetência escolar e perda de dias de trabalho pelos pacientes e seus familiares, estes podem chegar a atingir $1,3 \%$ da renda familiar anual (TERRERI; HILÁRIO; GOLDENBERG et al., 2002).

\section{TRAÇANDO OBJETIVOS E METAS PARA CONHECER O NOSSO PÚBLICO-ALVO}

Entendemos por educação tudo aquilo que é aprendido e vivenciado em todos os espaços, sejam eles formais ou não. Segundo Brandão (2001), nossa vida está misturada com a educação, e não há maneira de tentarmos escapar dela. Assim, para convivermos, para fazermos, para conhecermos, e principalmente, para sermos, estamos em constante processo educacional e de troca com os outros sujeitos, com os espaços e com os signos que nos cercam. 


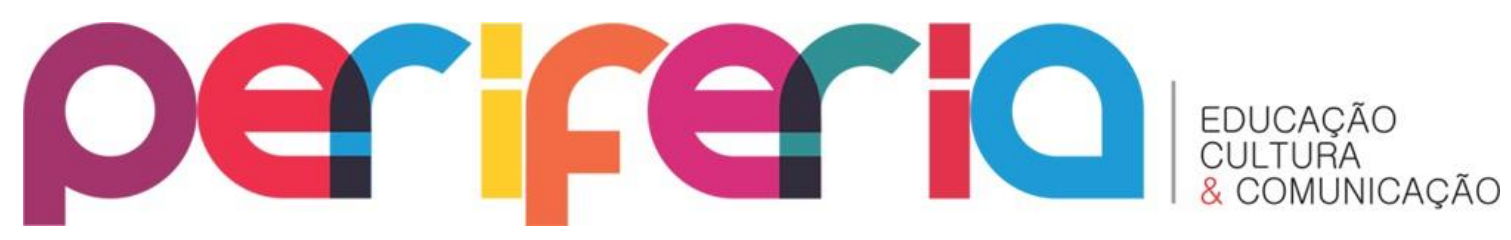

Nosso espaço de investigação é o Instituto Nacional de Cardiologia (INC). Um hospital federal, de alta complexidade, localizado dentro do município do Rio de Janeiro, que conta com uma equipe multidisciplinar (pedagogo, assistente social, médico, enfermeiro e psicólogo) de atenção à saúde, voltada para o atendimento de pacientes com FR, além de pesquisas e estudos em saúde coletiva.

Conhecemos e vivenciamos na prática a problemática de saúde que envolve o sujeito acometido pela $\mathrm{FR}$ e as consequências desse adoecimento em outros setores da sua vida. Diante disso, ao considerarmos que nos países em desenvolvimento existe uma diferença importante no que se refere às condições socioeconômicas, por conseguinte, no acesso aos serviços básicos, como saúde e educação, buscamos como objetivo geral, conhecer como foi o acesso desse sujeito à educação básica e identificar se o seu estado de saúde interferiu na sua trajetória escolar e, consequentemente, na sua escolaridade.

Brandão (2001) destaca que não existe um único modelo de educação. A escola não é o único lugar onde ela pode acontecer e o professor não é o único habilitado a ser o seu mestre e a "passar” o que sabe.

Segundo o dicionário Aurélio (FERREIRA, 2001), educação é um processo pelo qual há desenvolvimento da capacidade física, intelectual e moral de um sujeito. Educação é, portanto, uma questão de oportunidade, pois para que ela aconteça e alcance o seu ápice é necessário disponibilizarmos ao sujeito, meios para que ele a adquira, pois, os seres humanos não nascem com a expertise necessária para viverem sozinhos, eles dependem de modelos, de atenção, de acolhimento e de sujeitos que possam contribuir para o aprimoramento de suas habilidades, estimulando e favorecendo o seu desenvolvimento, enquanto cidadão.

Concomitante à educação temos o que consideramos como processo de escolarização, que é aquele modelo cuja educação formal é construída culturalmente pela sociedade vigente. Seu currículo costuma contemplar toda uma gama de conteúdos que é julgado como apropriado para garantir um 


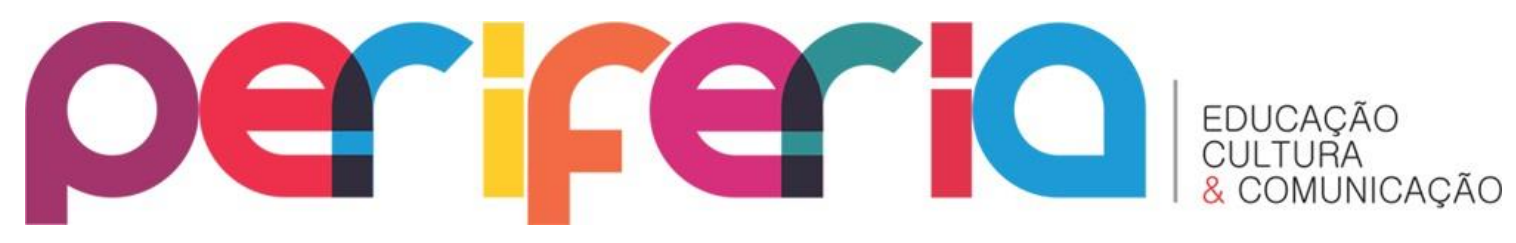

mínimo de conhecimento comum a todos, podendo ser mudado ao longo da história, de acordo com as demandas exigidas na época.

Podemos então, baseados nessas reflexões, dizer que essa investigação é resultante de inquietações oriundas do processo diário de observação e das atuações dos profissionais; e, de questionamentos relatados e/ou levantados pelos usuários, seus familiares e profissionais de saúde.

É também um desdobramento da pesquisa multicêntrica realizada em 2009 pelo INC e intitulada O Estudo das Propostas Terapêuticas na Cardite Reumática, na qual os médicos de centros de referência no tratamento da CR entrevistados, apontaram dificuldades na continuidade do tratamento de seus pacientes devido às condições socioeconômicas, dentre essas, o nível educacional dos mesmos e/ou de seus responsáveis.

Assim, foi realizada uma pesquisa bibliográfica sobre a temática a ser investigada: educação, doença crônica na infância e adolescência, escolarização e adoecimento e escolaridade dos responsáveis.

Num primeiro momento, foi definido que a metodologia estaria fundamentada nos pressupostos qualitativos de cunho exploratório, uma vez que uma das finalidades desse tipo de pesquisa é buscar esclarecer conceitos e ideias acerca de determinado fato. Além disso, queríamos que ela contemplasse uma abordagem descritiva, cuja intenção seria estudar as características e as relações entre as diversas variáveis que dão identidade a um determinado grupo (GIL, 1999).

A pesquisa foi dividida em duas fases:

$\mathrm{Na}$ primeira, foram definidos os critérios de inclusão para participar desse processo: 1. Deveria ser paciente cadastrado e acompanhado no ambulatório do hospital, independente do sexo; 2. 0 paciente deveria ter idade mínima de 18 anos; e, 3. Teria que ter realizado a cirurgia cardíaca valvar por consequência da febre reumática entre os 18 e 40 anos de idade. Nosso critério de exclusão considerou pacientes que habitassem fora da região metropolitana do Rio de Janeiro (o Instituto é referência nacional no tratamento das doenças cardiovasculares e pode receber pacientes de 


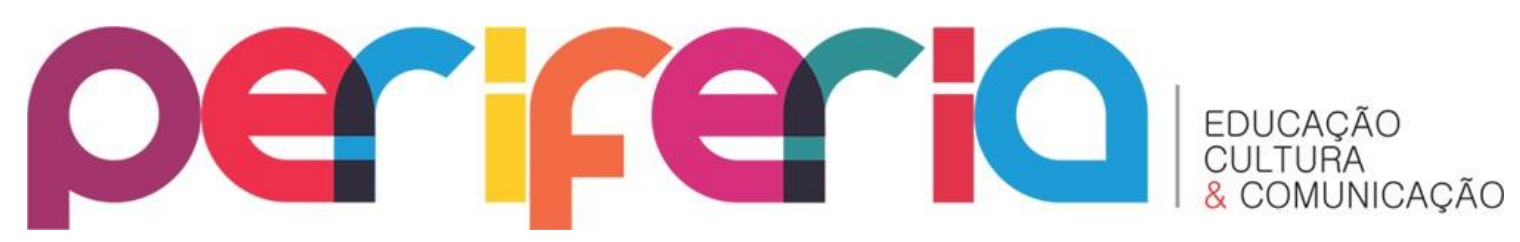

qualquer localidade do Brasil). A partir dos critérios definidos, 70 pacientes dentro do perfil definido foram identificados através do banco de dados de cirurgia cardíaca do INC.

A segunda fase consistiu em contactar os pacientes e verificar quais deles teriam disponibilidade de comparecer voluntariamente ao hospital, bem como o interesse em participar da pesquisa. Dentre esses, 06 pacientes cujas idades variavam entre 25 e 35 anos; se disponibilizaram a participar da pesquisa. Diante disso, as entrevistas foram agendadas para o mesmo dia do agendamento de sua consulta médica e/ou exames de rotina.

A escolha por sujeitos maiores de 18 anos ocorreu por conta da sua autonomia em participar da pesquisa, além de considerarmos que esses já teriam convivido com os diversos estágios da doença (uma vez que a mesma ocorre predominante na infância e adolescência) tendo assim uma certa vivência e uma história para contar.

Cabe aqui destacar que a proposta inicial foi de realizar entrevistas semiestruturadas, conduzidas sempre pelas próprias pesquisadoras (Quadro 1). 


\section{periferio}

Quadro 1: Perfil dos entrevistados.

\begin{tabular}{|c|c|c|c|c|}
\hline Nome & Sexo & Idade & Escolaridade & Local de Moradia \\
\hline Azaleia & Feminino & 34 & $\begin{array}{c}\text { Ensino médio } \\
\text { completo }\end{array}$ & Santa Cruz/RJ \\
\hline Margarintemo & Masculino & 26 & $\begin{array}{c}\text { Ensino médio } \\
\text { incompleto }\end{array}$ & $\begin{array}{c}\text { Duque de } \\
\text { Caxias/RJ }\end{array}$ \\
\hline Rosa & Feminino & 28 & $\begin{array}{c}\text { Ensino Médio } \\
\text { completo }\end{array}$ & Santa Cruz/RJ \\
\hline Cravo & Masculino & 27 & $\begin{array}{c}\text { Ensino Médio } \\
\text { completo } \\
\text { Técnico } \\
\text { completo }\end{array}$ & São Gonçalo/RJ \\
\hline Lírio & Masculino & 30 & $\begin{array}{c}\text { Ensino Médio } \\
\text { incompleto }\end{array}$ & Campo Grande/RJ \\
\hline
\end{tabular}

Fonte: Elaboração das autoras (2017).

O objetivo desse instrumento era verificar que aspectos interferem; nas condições de vida (passada e presente), principalmente no que tange à sua educação. Em virtude disso, tínhamos questões que giravam em torno dos seguintes aspectos: seu estado civil, ter ou não filhos, sua situação de saúde, o impacto social, a necessidade de hospitalização, o tempo de internação, os cuidados dispensados à sua saúde, a história do período escolar, a sua trajetória escolar com ênfase no antes e no depois da descoberta da doença, se houve prejuízo escolar - se interrompeu os estudos e em caso positivo o porquê, a escolaridade dos irmãos e responsáveis, a sua formação profissional.

0 tratamento que dispensamos aos dados obtidos; se deu a partir dos pressupostos teóricos que envolve a análise do discurso. Esse processo tem como objetivo avaliar os sentidos atribuídos às diversas formas de linguagem,

\footnotetext{
${ }^{5}$ Respeitando as questões éticas da pesquisa, todos os nomes foram substituídos. Num hospital é muito frequente um paciente ser denominado por um número ou o seu diagnóstico, algo que incomoda, e é relatado por muitos. Optamos, portanto, para expor essa análise, substituir o nome original de nossos entrevistados por nomes de flores, tendo em vista que essas, assim como os seres humanos, para que possam cumprir o seu ciclo de vida, precisam de alguns cuidados para o seu pleno crescimento e desenvolvimento.
} 


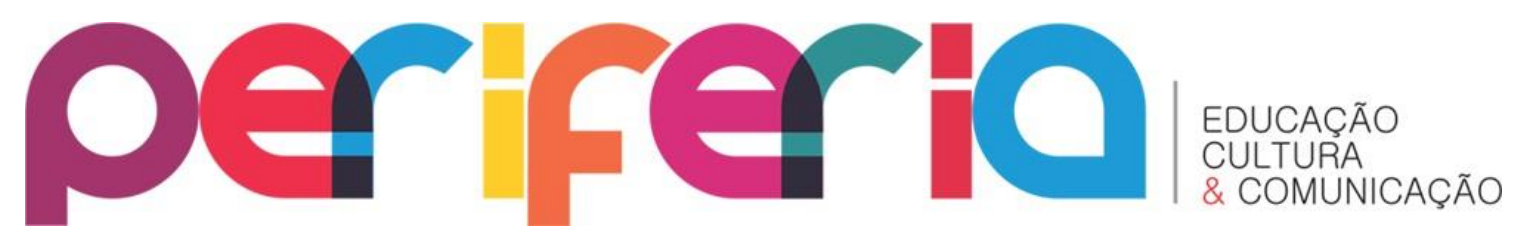

sejam elas verbais ou não. Nesse caso, basta que esse material produza alguma interpretação para a investigação, assim, a linguagem, o sujeito e a sua história tem íntima relação com a língua que ele expressa e com a sua ideologia, ou seja, o que ele expressa, o que pensa, o que sente e como se vê no mundo (CAREGNATO; MUTTI, 2006).

Segundo Caregnato e Mutti (2006), esse tipo de análise trabalha com o sentido daquilo que é expressado, não é uma tradução, mas sim uma produção constituída por uma: ideologia, isto é, geralmente as ideias verbalizadas por esse fazem parte de uma representação do coletivo; por uma história - aqui representado pelo seu contexto social e histórico; e a linguagem - que é a materialização do texto. A linguagem, portanto, vai além do texto produzido; ela é reflexo de algo já pré-construido, são os sentidos que o sujeito pretende dar à sua fala.

Ainda, segundo as autoras, a análise do discurso compreende que nada novo será descoberto, o que será feito é uma releitura daquilo que provavelmente já tenha sido dito. Além disso, esse tipo de análise não tem a menor pretensão de dizer o que é certo ou errado, pois nenhum ator envolvido estará sendo julgado.

Para Foucault analisar o discurso é tentar compreender as relações históricas de poder e saber, que envolvem e estão presentes no que é falado (entrevistas, gravações, etc.), ou escrito (textos, livros, reportagens, etc.). 0 discurso é, portanto, a soma do sujeito, do contexto e da materialidade do discurso (apud FISCHER, 2001).

Não há, portanto, uma descontextualização das falas, já que estas estão inscritas em condições concretas de vida dos sujeitos que as vivenciam em sua cotidianidade, através do local de moradia, do tipo de transporte e tempo que levam para chegar ao trabalho ou a escola, do acesso à rede básica de saúde, da renda familiar, da participação ou não em atividades culturais, esportivas e de lazer.

A interpretação desse discurso é, portanto, um gesto que simboliza, que torna concreto, que dá visibilidade às falas, pois para haver interpretação 


\section{periferio}

é necessário dar sentido a mesma. No entanto, vale ressaltar que essa interpretação também é influenciada pelo sujeito que a interpreta, uma vez que esse, por sua vez, traz consigo suas concepções de mundo, seus sentimentos, suas crenças, bem como suas vivências e experiências de vida (CAREGNATO; MUTTI, 2006). Enfim, na análise de discurso, há uma relação intrínseca entre o locutor, o enunciado e o mundo.

Apesar de termos concentrado nossas atenções e enfatizado a questão da educação e trajetória escolar, a partir dessas entrevistas algumas categorias foram elencadas, dentre as quais destacamos (Quadro 2):

Quadro 2: Categorias.

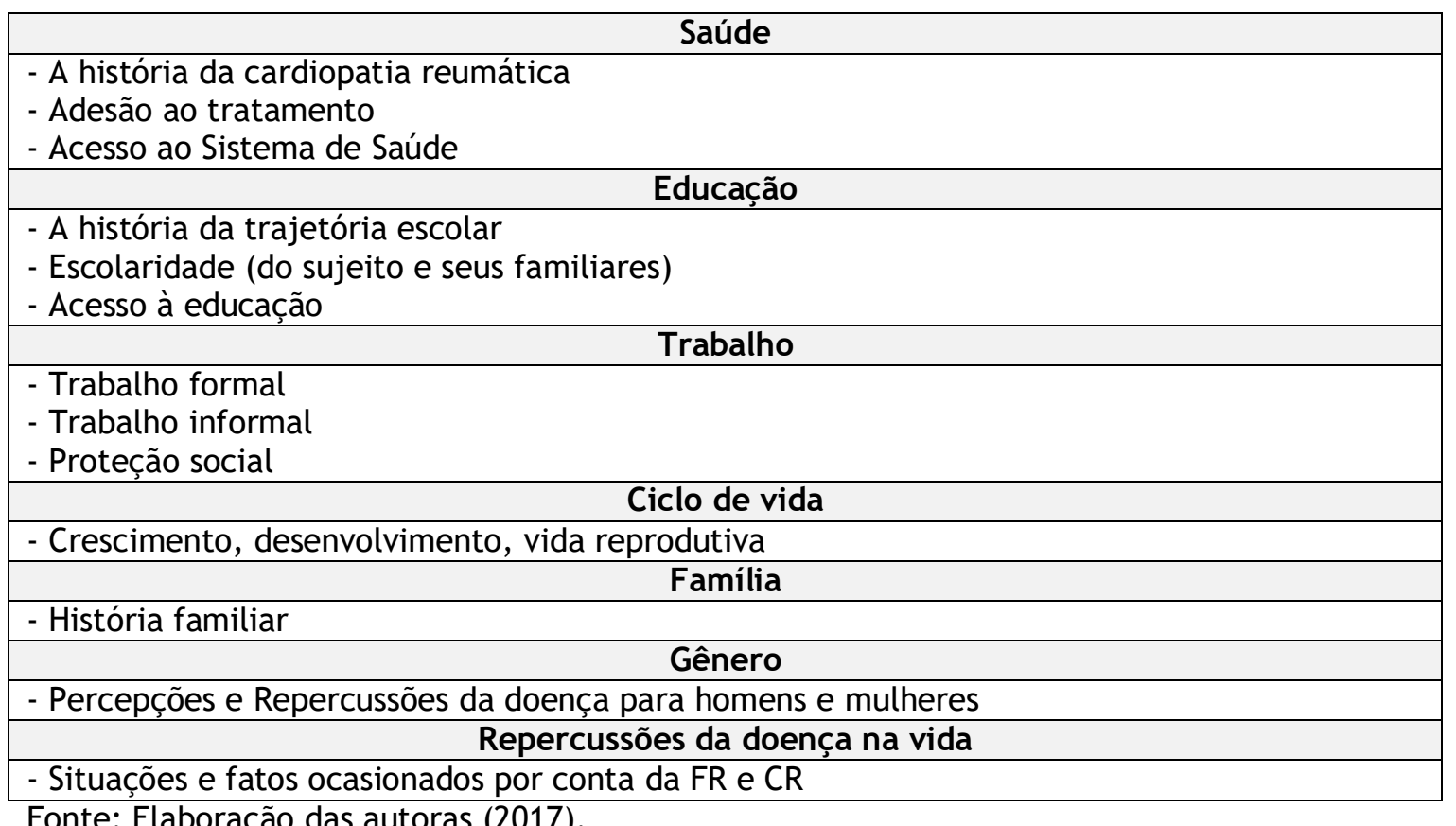

Fonte: Elaboração das autoras (2017).

Percebemos que, à medida que essas entrevistas foram sendo realizadas, as mesmas estavam se aproximando da metodologia de história de vida ${ }^{6}$. Ainda que tivéssemos um roteiro a ser seguido, os entrevistados

\footnotetext{
${ }^{6}$ História de vida é uma metodologia utilizada na pesquisa qualitativa que vem ganhando cada vez mais espaço em estudos na área de Educação Especial e Inclusiva. Consiste em ouvir o relato de vida do sujeito entrevistado/biografado considerando a sua narração pelo seu ponto de vista (GLAT; PLETSCH, 2009).
} 


\section{periferio}

acabaram se utilizando de uma fala espontânea para expressar questões que, de certa forma, os incomodavam. Muitas vezes a proposta inicial de perguntas "pré-estipuladas" foram substituídas por relatos onde ambos (entrevistador e entrevistado) julgaram importante serem ditos/ouvidos.

Ocorreram situações, por exemplo, em que as entrevistadoras tiveram dificuldade em retomar o assunto iniciado e acabaram privilegiando esses relatos, ou seja, acabamos deixando a conversa fluir, e na maioria das vezes tais histórias, eram carregadas de muita emoção, e de uma mistura de muitos sentimentos. Consideramos que esses momentos foram fundamentais para a nossa investigação.

Aqui convém destacarmos que esse discurso vai ao encontro do que nos coloca Glat e Antunes (2014, p.53), quando mencionam que, quando damos voz ao sujeito para que ele relate aspectos sobre sua vida, estabelecemos com este uma relação de horizontalidade, pois ninguém produz conhecimento sozinho, ou seja, precisamos sempre de outro alguém. Ainda de acordo com as autoras isso permite que grupos "silenciados ou marginalizados" sejam de alguma forma ouvidos e se reafirmem como protagonistas de sua vida, e da história que nela escrevem.

Essa metodologia acaba por romper com paradigmas existentes no campo das Ciências Humanas, uma vez que nela é impossível o pesquisador se manter neutro naquela situação. Aqui o que prevalece é a narrativa contada de forma espontânea e o respeito ao fluxo e à história que esse sujeito quer expor. Convém dizer que esse tipo de metodologia ainda não ocupa um lugar de destaque entre as demais metodologias e ainda é pouco utilizada no meio acadêmico (GLAT; ANTUNES, 2014). 


\section{periferio}

PROPONDO UMA DISCUSSÃO ACERCA DA INCLUSÃO DA PESSOA COM FEBRE REUMÁTICA NA SOCIEDADE E DO ACESSO E GARANTIA DO DIREITO À EDUCAÇÃO

Essa investigação buscou encontrar explicações sobre o processo de adoecimento e suas repercussões sociais, no que se refere à educação e à trajetória escolar do sujeito com cardite reumática.

Segundo Glat e Antunes (2014) não há melhor informante sobre o seu processo de aprendizagem, de acesso à escola e de escolarização do que os próprios sujeitos que o vivenciam.

Nosso levantamento bibliográfico inicial mostrou que, apesar do discurso sobre a importância da educação para todos, nada se fala especificamente sobre os sujeitos que passam por longos períodos de hospitalização por conta do acometimento cardíaco e tem o seu direito à educação, nesses momentos, interrompido por conta desse evento.

Crianças e adolescentes com FR têm em seu quadro de adoecimento uma evolução com lesões nas válvulas cardíacas, necessitando não raro de intervenções cirúrgicas, algumas vezes, múltiplos procedimentos, permanecendo internados por longos períodos, o que acarreta o afastamento do meio familiar, de seus amigos, bem como das suas atividades diárias e sociais, incluindo a escola.

A educação, por sua vez, faz parte da formação do ser humano e pode ocorrer de diversas maneiras, em diversos tempos e em diferentes espaços. Vivemos educação desde o dia em que nascemos. No entanto, a vida moderna impulsionou a criação de uma instituição responsável por educar crianças e adolescentes à qual foi dado o nome de escola (ALVES, 2000). No que se refere à educação escolar, ainda temos muitos desafios a serem superados, principalmente àqueles vividos por grupos excluídos historicamente.

Segundo Lima (2015), com um olhar histórico sobre a educação, podemos perceber que desde a Antiguidade tem sido difícil a luta pela inclusão de alunos com deficiência ou com doenças crônicas. Cabe destacar que, segundo Glat e Blanco (2007), a própria deficiência era vista como uma 


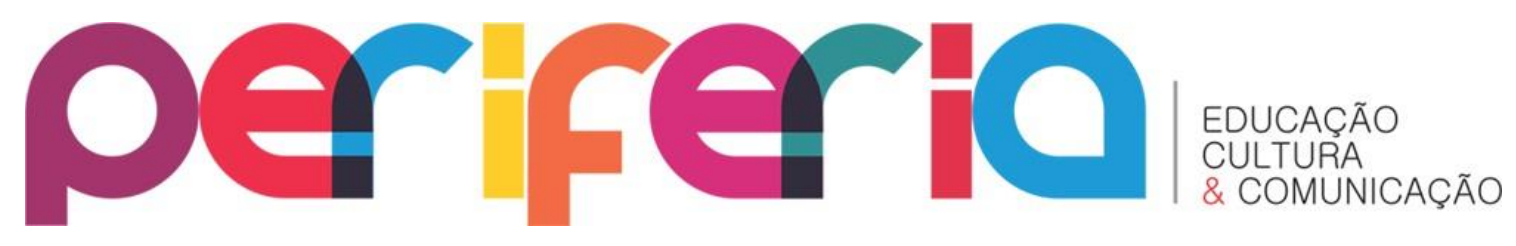

doença crônica, e todo o atendimento voltado para esse público, mesmo quando a intenção era educacional, ocorria pelo viés terapêutico, sendo as possíveis intervenções orientadas por pareceres médicos e/ou psicológicos.

Consideramos como legislações importantes para essa discussão a promulgação da Constituição Federal de 1988, na qual considera em seu Art. 205 que a educação é direito de todos e dever do Estado e da família e no Art. 208 (VII) reforça as ações de atendimento ao "educando, em todas as etapas da educação básica, por meio de programas suplementares de material didático-escolar, transporte, alimentação e assistência à saúde" (BRASIL, 1988). O Estatuto da Criança e do Adolescente (ECA), que em seu Art. 53 traz como direito da criança e do adolescente "à educação", visando o pleno desenvolvimento de sua pessoa, preparo para o exercício da cidadania, e qualificação para o trabalho" (BRASIL, 1990).

Além disso, temos os documentos originados pelas Conferências de Jomtien (1990), de Salamanca (1994) e Convenção da Guatemala (1999) que trazem no seio de sua discussão o acesso à educação por todos os sujeitos independente de suas necessidades específicas; bem como a Resolução 41/95, que institui o direito da criança e do adolescente hospitalizado (BRASIL, 1995); a Lei de Diretrizes e Bases da Educação Nacional n. 9.394/96 que, em seu Art. $58\left(\S 2^{\circ}\right)$ entende que 0 atendimento educacional poderá ser realizado "em classes, escolas ou serviços especializados, sempre que, em função das condições específicas dos alunos, não for possível a sua integração nas classes comuns de ensino regular que garante a todos o direito à educação" (BRASIL, 1996); e a Resolução CNE/CEB n 2/01 (BRASIL, 2001) cuja instituição da obrigatoriedade do atendimento pedagógico nos hospitais fica evidenciada (BRASIL, 2001).

Embora tenhamos determinações legais avançadas, no que se refere ao direito à educação, independente do espaço escolar, esbarramos numa constatação: o paciente com doença crônica não tem o seu direito totalmente assistido quando há a necessidade de hospitalizações prolongadas e acompanhamentos médicos frequentes por um longo período (que resultam 


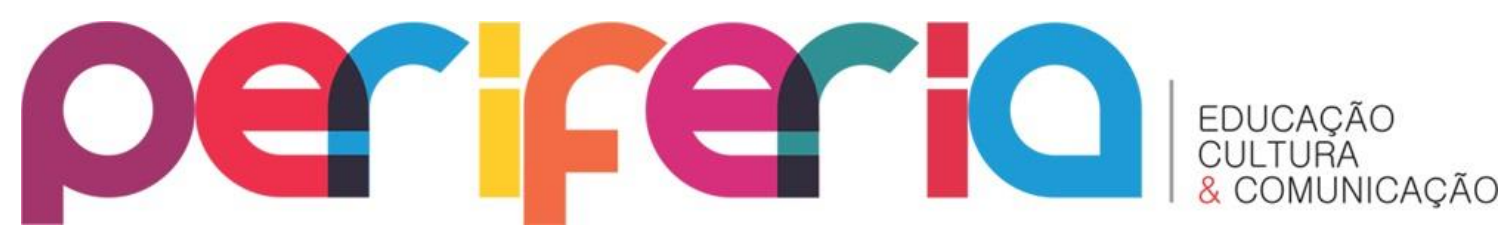

em faltas na instituição escolar de origem), como as ocasionadas pelas cirurgias cardíacas.

Uma de nossas entrevistadas, Rosa, faz o seguinte relato ${ }^{7}$ quando fala de seu período escolar:

Foi bom, eu era responsável, nunca repeti de ano. Pra dizer que nunca repeti o ano, no ano que eu operei, eu acabei perdendo o ano letivo, mas eu sempre fui uma boa aluna, minha mãe na época ela não trabalhava, meu pai era pedreiro, tem serviço quando tem obra; não tem obra, não tem serviço. Ah eu falei: vou ter que fazer alguma coisa, de repente fazer faculdade, mas eu tenho que fazer alguma coisa, me formar em alguma coisa. Na realidade os meus irmãos por parte de pai terminaram o segundo grau e pararam ali. 0 meu irmão ((fala o nome do irmão)), eu falo para ele, faz algum curso, faz alguma coisa, né? A minha época de escola foi bom, fui bem, nunca repeti de ano, a não ser realmente quando eu tive este problema no coração que eu perdi o ano letivo. $\mathrm{Na}$ verdade eu comecei a ficar doente, eu já comecei a perder vários dias de aula, até que eu vim pra cá ((INC)) só aqui, eu fiquei dois anos, não, dois meses internada, aí dois meses ficaram pra trás e até eu sair daqui pra me recuperar, eu já tinha, a diretora conversou com minha mãe, não tem jeito, mesmo que traga atestado.

O relato de Rosa nos traz outra constatação: os acompanhamentos educacionais em âmbito hospitalar podem acabar não ocorrendo, ora porque as instituições privadas hospitalares não possuem, em seu corpo de funcionários, profissionais de educação direcionados para o trabalho pedagógico/acompanhamento curricular com crianças e adolescentes, e/ou porque não possuem, no caso de instituições públicas, convênio com a Secretaria de Educação, que, por intermédio de parceria, costuma implantar classes hospitalares para o atendimento desse público, no caso das internações prolongadas.

\footnotetext{
${ }^{7}$ Mantivemos na integra todos os relatos, além disso utilizamos "..." para as interrupções de fala do entrevistado e "(( ))" para alguma explicação e/ou complementação necessária para compreensão do leitor.
} 


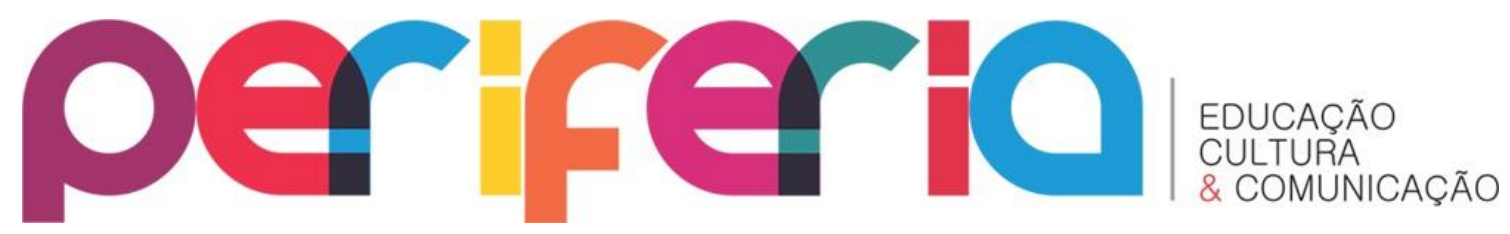

Apenas uma de nossas entrevistadas, Margarida, teve acesso à classe hospitalar no período de sua internação, e nos traz o seguinte depoimento:

$\mathrm{Na}$ minha escola foi difícil, porque eu ficava mais internada do que em casa, então eu conseguia fazer, né? Completar a série. Aqui no hospital; primeiro eu fiquei no Menino Jesus, tinha ajuda dos professores, só depois que eu fui para o Ensino Médio melhorou um pouco. Mesmo atrasada; só que eu fiquei muito atrasada no Ensino Médio; aí foi depois da última cirurgia, que eu consegui assim completar certinho, sem ter que interferir na cirurgia ou internação. No Menino Jesus vinha uma pedagoga, né? Trabalhava no Hospital ((Margarida se refere à classe hospitalar)). Hoje tem apostila, antigamente não tinha apostila, não tinha como acompanhar a matéria que a professora dava na escola, na sala de aula; então ela dava por base o que a série assim, precisava, né? A matéria, né? Da série e fazia assim, todos dias uma hora, uma hora e meia pra poder fazer a prova; porque às vezes quando eu ficava em casa ia à escola só pra poder fazer a prova ou a minha mãe levava a prova pra eu fazer no hospital.

Nesse relato, Margarida se refere às ações desenvolvidas no Hospital Municipal Jesus, localizado na zona norte do município do Rio de Janeiro. Foi nesse hospital que ocorreu a implantação da primeira Classe Hospitalar que se tem notícia no Brasil, através de um convênio firmado entre a Secretaria Municipal de Saúde e a Secretaria Municipal de Educação em 14/08/1950 (FONSECA, 2001). O objetivo era, e ainda é, atender educacionalmente as crianças dos segmentos da Educação Infantil e do Ensino Fundamental.

Seu surgimento acontece na ocasião em que a poliomielite (hoje erradicada no Brasil) era responsável pelo grande número de internações de crianças, ou seja, o foco central da ação educativa era possibilitar um atendimento específico para deficientes físicos. Talvez, seja esse o motivo, para que a atuação do profissional de educação e o atendimento a estas crianças no hospital estejam vinculados à educação especial (SCHILKE, 2003). 


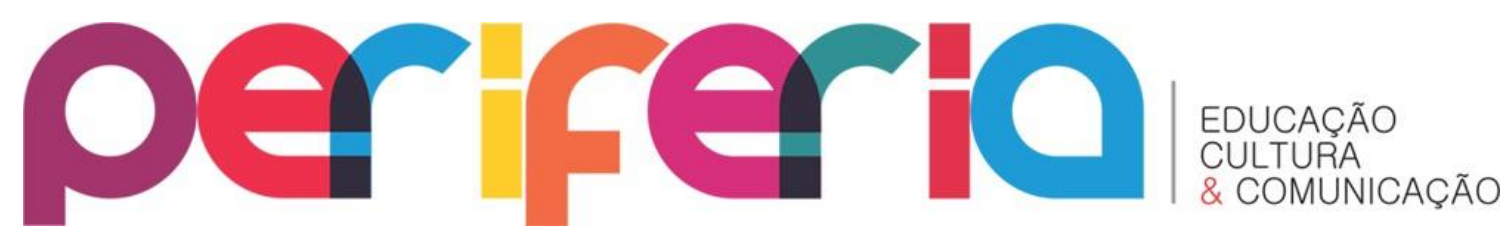

Para efeitos legais de atendimento é considerado público alvo da educação especial a pessoa com deficiência, transtornos globais do desenvolvimento e altas habilidades/superdotação conforme determina a Política Nacional de Educação Especial na Perspectiva da Educação Inclusiva (BRASIL, 2007), mas não o sujeito que tem doença crônica e precisa ficar afastado por longos períodos da escola, como é o caso desses pacientes.

Os sujeitos com doenças crônicas, por exemplo, acabam sendo considerados como público-alvo da educação especial, de acordo com o entendimento da lei, apenas durante o período de internação, por assim dizer, sendo garantido nesse caso, o atendimento em classes hospitalares. Mas e, se no hospital não existir classe hospitalar e/ou atendimento pedagógico hospitalar? Evidenciamos aí uma fragilidade na lei, que não respalda e nem dá suporte à grande maioria, durante a sua internação e, principalmente, quando esses já estão aptos a retornarem à sua instituição escolar de origem.

Corre-se aqui o risco de esses cidadãos, antes estudantes, e com direito à educação (conforme determinam as nossas leis), serem esquecidos quando se tornam pacientes e tem direito ao acesso à saúde, cabendo aqui dizer, que um direito não deveria anular o outro.

Cravo, outro participante, nos traz a seguinte exposição sobre a sua experiência escolar, na qual evidencia ter perdido o ano letivo (história que se repete constantemente) assim que a doença piorou e precisou ficar afastado por um longo período da escola:

Meu período de escola foi ótimo. Eu não tinha repetido até vir pra cá ((INC)) internar... eu tava no terceiro ano do ensino médio quando a endocardite atacou a válvula, destruiu a válvula e eu tive que ficar internado... e pelo fato de ficar internado eu repeti o terceiro ano. Do nível médio... o último... eu tinha 17 anos... eu nunca tinha repetido... certinho... aí por conta disso eu fiquei aqui se não me engano 4 meses internado... aí quando sai daqui que eu terminei o ensino médio, mas sempre fui aluno assim... nunca fui de tirar muita nota vermelha... até tirava algumas, mas sempre passava. 


\section{periferio}

É certo que o acompanhamento escolar também pode ser realizado através do atendimento em ambiente domiciliar, conforme Resolução CNE/CEB n 2 (BRASIL, 2001). Mas é certo também que nem todos têm acesso a esse tipo de serviço quando necessária a sua utilização.

A questão é que esses sujeitos apresentam comprometimentos pelo resto de sua vida: não podem realizar grande esforço físico, por exemplo. Então, é bem possível que não possam participar das aulas de educação física, e quando jovens adultos, caso não tenham um grau de escolaridade avançado, que thes permita desenvolver atividades que não exijam muito esforço físico, podem estar fadados, infelizmente, aos subempregos (esses, sim, exigem!) e muitas vezes, sem carteira assinada.

Ceccim (1997) destaca em seu artigo que o processo de adoecimento e uma possível internação perpassam o corpo e as emoções dos sujeitos que os vivenciam, passam também por sua cultura e relações produzindo afetos e possibilitando novos conhecimentos sobre si mesmo e sobre o outro, além obviamente, dos relacionados à saúde e à doença. As relações de cuidado, de proteção e da vida ficam impregnadas de informações, de conhecimento e de saber pessoal.

Crisântemo faz o seguinte relato em relação à trajetória escolar e de como a doença interferiu na sua vida social.

Ah, eu desanimei porque gostava muito de fazer bagunça ((risos)). Aí o pessoal da bagunça todo passava de ano e eu fui ficando pá trás. Ah, assim eu, já era pra eu ter terminado há bastante tempo, mas fiquei doente... aí tive que parar de estudar... eu acho que eu fui reprovado umas quatro vezes mais ou menos. Eu tava quase na metade do ano, tive que parar de estudar, para me tratar, fiquei internado, aí isso atrapalhou bastante. Ah, eu passava mal, aí não ia para a escola, perdia prova. Gostava muito de fazer educação física, às vezes não podia fazer, aí ficava meio chateado; gostava de jogar bola. Isso atrapalhou. Gostava da escola, dos amigos, da bagunça, das namoradas ((risos)). Quando 


\section{periferio}

tinha uns 14 anos eu fiz uma valvuloplastia, cheguei passando mal, cheguei... aí fiz uma valvuloplastia, aí durou um ano também. Aí durou um ano, eu comecei a sentir mal de novo, aí vim pra cá ((INC)), fiquei internado aqui, fiquei bastante tempo internado, aí operei de novo, aí melhorei um pouco, aí fiquei me cuidando, aí fui ficando adolescente, uns quinze, dezesseis, aí me revoltei e parei de tomar remédio; minha mãe mandava eu tomar remédio eu fingia que tomava e jogava fora, aí parei também de tomar Benzetacil né? Aí juntou tudo, aí eu fiquei ruim de novo. Ruim de novo, operei, botei uma válvula, botei um válvula, aí... fiquei cuidando; aí com o passar do tempo fui ficando, me desgastando, não sei porque; aí eu... operei de novo. Acho que neste tempo aí eu não tinha como ir para escola porque eu sentia bastante dor, chorava, aí atrapalhava bastante.

Podemos destacar que há muitas variáveis que podem interferir na educação e na trajetória escolar desses sujeitos, dentre elas, principalmente: condição de saúde (o adoecimento em si e a busca pelo tratamento); adesão ao tratamento (a administração da penicilina - medicamento de primeira escolha para a profilaxia primária e, principalmente, a administração regular da penicilina para a profilaxia secundária, que é dolorosa, o que acarreta muitas vezes, o abandono e a recidiva da doença); o acesso à saúde (não raro, ouvimos relatos de diagnóstico tardio por conta da dificuldade de acesso à atenção primária de saúde); condições familiares (condições sociais, econômicas e culturais podem interferir diretamente) e; gênero (a doença e a problemática que envolve esse adoecimento é vivenciada de maneira diferente por homens e mulheres).

Lírio destaca a relação da necessidade do trabalho e garantia de renda ao ser questionado pela pesquisadora o porquê de ter parado de estudar mostrando a dificuldade em conciliar as duas atividades.

Comecei a trabalhar cedo, ficou difícil conciliar as duas coisas juntas. Quando eu comecei a trabalhar eu comecei a trabalhar na parte da noite, eu até tentei 


\section{periferio}

continuar estudando, mas ficou difícil todos os dias, aí fazer provas, estudar para as provas e também pelo fato de acordar cedo para ir para a escola, no caso acordava onze horas da manhã. Chegava às 7 horas da manhã tinha que acordar às onze, aí quando saía da escola ia para o trabalho de novo. Aí eu fui, e optei por continuar só trabalhando. Um dia eu pretendo voltar a estudar, falta vergonha na cara.

O trabalho e a dificuldade de entrada no mercado de trabalho formal por conta da cicatriz e dos possíveis afastamentos e possíveis incapacidades do sujeito também foram relatados por nossos entrevistados, mostrando ainda um pré-conceito enraizado culturalmente em nossa sociedade.

Margarida evidencia isso em outro trecho do seu relato quando faz uma exposição sobre a experiência de buscar emprego no mercado de trabalho formal.

$\mathrm{Na}$ entrevista ((de emprego)) é bem complicado. Por mais que você não fale, se você botar uma coisa que mostre a cirurgia ((eles já perguntam)) "você tem uma cirurgia, mas o que aconteceu; é grave, você faz acompanhamento, você passa mal?" Eles pensam que a pessoa sempre está em falta, assim, de cuidados, que precisa muito de cuidados. A gente precisa de cuidado, mas só que não é uma coisa que, evita de fazer certas coisas, tipo o que eu faço, não evita, eu faço o meu trabalho normal, seria uma dificuldade, é cansativo, mas todo o trabalho é cansativo.

Lírio traz um outro enfoque que poderíamos associar à questão de gênero e a dificuldade de encontrar posto no mercado de trabalho para quem passa por esse tipo de doença.

A única dificuldade é que, às vezes tem uma bobina lá, de embalagem, que no caso, pesa $30 \mathrm{~kg}$, aí quando, é o que eu expliquei pra senhora, como eu tenho um vínculo de amizade com o patrão, ele pede para que alguém me ajude para carregar o peso. E quando não tem jeito sou obrigado a pegar, porque eu nem sempre gosto de estar 


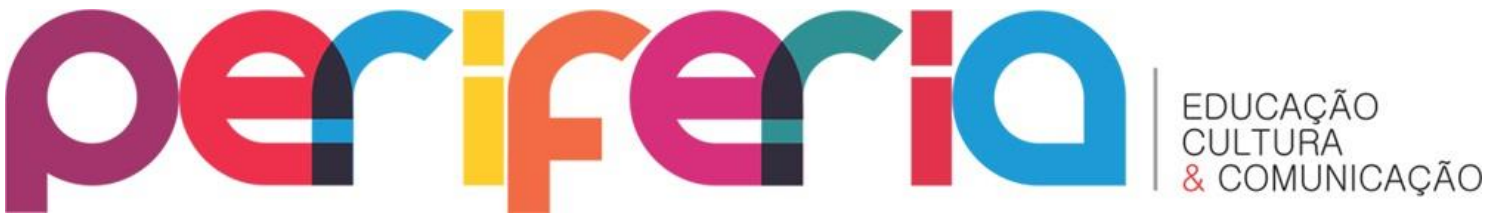

pedindo às pessoas para fazer as coisas para mim. Aí eu pego. É aí onde eu fico. Dificuldade não tenho, até porque até mesmo, o cara ((diz o nome de um amigo do trabalho)) que trabalha comigo é meu irmão, entendeu? Então ele sempre está lá. Às vezes que eu peço para ele fazer alguma coisa pra mim, ele está sempre fazendo, mas só que, a senhora sabe como é que é homem né, às vezes ele está fora e eu não quero esperar, para adiantar o serviço, aí eu vou eu mesmo, pego e faço ((no diálogo a pesquisadora questiona se ele sabe as consequências disso e se vale a pena correr o risco, uma vez que esses pacientes ficam com restrição de carregar peso por conta da cirurgia cardíaca)) eu sei... Vale sim...

Por outro lado, constatamos em seus relatos, que a maioria dos nossos entrevistados tem um nível de escolaridade superior ao de seus responsáveis, o que representa um avanço educacional entre uma geração e outra.

A grande maioria alega ter parado de estudar em virtude do tratamento, das idas constantes ao hospital, do cansaço físico e mental por conta do adoecimento, o que gera um grande desgaste físico e emocional.

Embora dois do total já entrevistados digam terem formação técnica na área da saúde, seus relatos dialogam com os dos demais, quando os mesmos contam a história de sua trajetória escolar, marcados pelo afastamento, justamente a partir da descoberta da doença. Cabe aqui destacar, que um trabalha na área de saúde, porém não tem carteira assinada e nenhum direito a qualquer benefício social, caso seja afastado por motivo de doença, por exemplo.

\section{PARA FINALIZARMOS}

Cada vez mais o hospital tem se mostrado como um espaço para a prática e de pesquisa para profissionais da área da educação. Segundo Fontes e Vasconcellos (2007), o número de artigos publicados ainda é muito pequeno comparado a outras áreas, o que de certa maneira aponta uma fragilidade e a 


\section{periferio}

necessidade de mais investigações que possam compor um corpus de conhecimentos e saberes científicos.

Nosso foco foi para as questões relacionadas ao âmbito educacional e mesmo que tenhamos feito um recorte para essa nossa discussão, os dados dessa pesquisa buscaram incorporar em sua concepção uma visão mais ampliada de saúde, compreendendo que no processo de saúde-doença, há determinantes sociais, que interferem diretamente em sua composição, ou seja, indo além dos aspectos biológicos, físicos e psicológicos, abrangendo questões socioeconômicas, tais como: educação, cultura, habitação, transporte, saneamento básico, esporte, lazer e localização geográfica.

Nossos entrevistados descreveram como foi a sua vida desde antes do diagnóstico, o momento da descoberta da doença, a relação com os seus familiares, os desafios diante da busca pelo tratamento, seus namorados(as) e/ou companheiros(as), as complicações do período gestacional, a relação com os filhos, o acesso à educação e de sua trajetória escolar, da escolaridade e saberes populares de seus respectivos pais, de suas profissões, bem como de sua inserção e manutenção no mercado de trabalho.

Para Minayo (1999), esse processo expressa a realidade social e para que possamos ter uma compreensão aproximada de sua totalidade se faz necessário examiná-lo a partir dos diferentes contextos: econômico, político e cultural no qual vivemos. Ainda, segundo a autora, dentro de uma sociedade capitalista como a nossa, "as relações sociais se fazem a partir de diferenciação de classes, da desigualdade na distribuição e atribuição de riquezas, a concepção de saúde/doença está marcada (também) por essas contradições" (MINAYO, 1999, p. 179).

Nesse sentido, demonstrar as especificidades da doença em cada indivíduo e os custos sociais do adoecimento, principalmente no que se refere à educação e, consequentemente, sua trajetória escolar e formação profissional, é fundamental para o investimento nas políticas públicas de prevenção e intervenção que ressaltem a necessidade de um olhar mais ampliado. 


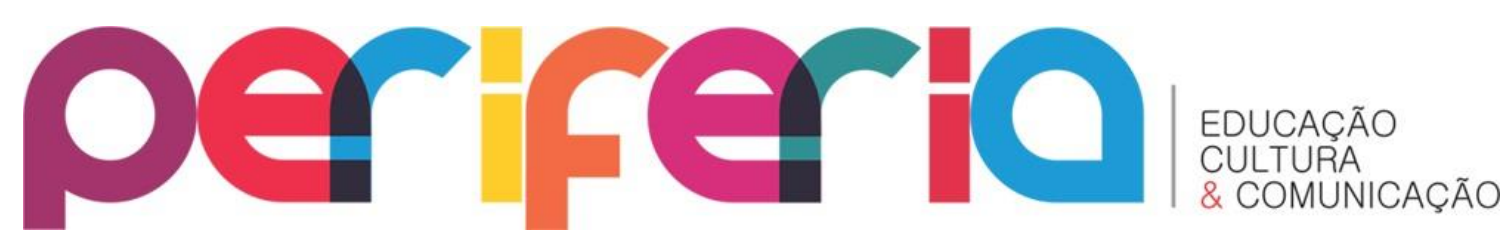

Assim, o que esperamos ao final dessa pesquisa é contribuir para a reflexão sobre a situação de educação, escolarização e saúde de sujeitos acometidos por doenças crônicas, como é o caso dos nossos pacientes. Acreditamos que temos políticas de educação e saúde avançadas, mas que na prática acabam por não contemplar todos os cidadãos ou continuar reforçando a exclusão, uma vez que uns tem acesso, mas a grande maioria não.

Em nossa pesquisa, apenas uma de nossas entrevistadas teve acesso ao atendimento educacional e/ou pedagógico durante 0 período de hospitalização, mas nenhum relata acompanhamento no seu regresso à sua unidade escolar de ensino regular, inclusive 100\% de nossos entrevistados relataram terem perdido o ano letivo quando tiveram que ficar internados.

Consideramos que o diagnóstico da doença é fator de destaque na vida desses sujeitos, mas não podem comprometer nem privá-los do acesso ao direito à educação, por exemplo, salvo em condições onde a manutenção da vida deva prevalecer.

Acreditamos, portanto, que todos tinham capacidade de terem sido acompanhados educacional e/ou pedagogicamente por profissionais formados e disponibilizados para essa função, se isso existisse conforme determina a lei.

Cabe aqui destacar, que futuras consequências podem ser amenizadas por políticas de prevenção efetivas e capazes de fazer com que futuras crianças e adolescentes não cheguem à mesa de cirurgia, e, caso cheguem, tenham seu direito à saúde, à educação e a uma formação profissional, de fato, assegurados.

É importante ressaltarmos que a problemática que envolve o processo de adoecimento (assistência médica e de equipe multidisciplinar por longos períodos, tratamentos dolorosos e possíveis intervenções cirúrgicas) não pode afastar e nem tirar do sujeito o seu direito do exercício a plena cidadania, nesse caso, da garantia do seu acesso à educação, bem como do seu acompanhamento e de sua permanência na escola. 


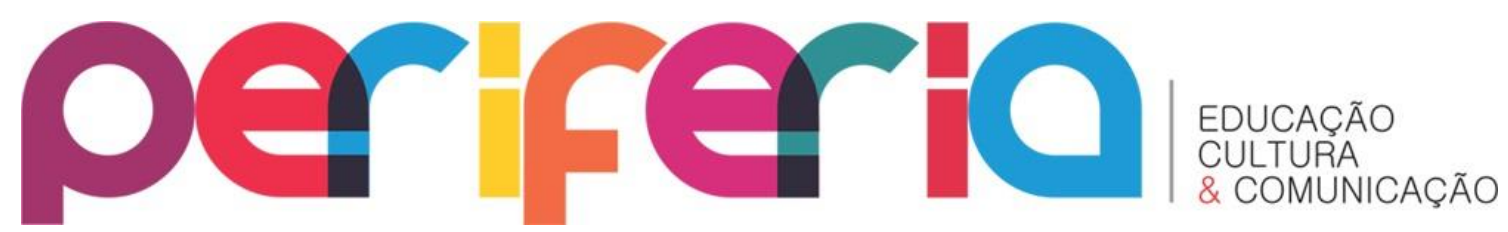

\section{REFERÊNCIAS}

ALVES, N. Espaço e tempo de ensinar e aprender. In: CANDAU, V. M. (org). Linguagens, espaços e tempos no ensinar e aprender (ENDIPE). Rio de Janeiro: DP\&A, 2000.

BRASIL. Lei $n^{\circ} 8.069$, de 13 de julho de 1990.

Dispõe sobre o Estatuto da Criança e do Adolescente e dá outras providências. Disponível em:

<http://www.planalto.gov.br/ccivil_03/leis/L8069Compilado.htm> Acesso em: 31 jan. 2017.

. Constituição da República Federativa do Brasil de 1988. Disponível em: <http://www.planalto.gov.br/ccivil_03/Constituicao/Constituicao.htm> Acesso em: 31 jan. 2017.

. Resolução no 41 de 13 de outubro de 1995. Dispõe sobre os direitos da criança e do adolescente hospitalizado. Conselho Nacional dos Direitos da Criança e do Adolescente - CONANDA. Disponível em: <http://dh.sdh.gov.br/download/resolucoes-conanda/res-1-a-99.pdf $>$ Acesso em: 31 jul. 2016.

. Resolução CNE/CEB n 2, de 11 de setembro de 2001. Institui Diretrizes Nacionais para a Educação Especial na Educação Básica. Disponível em: <http://portal.mec.gov.br/cne/arquivos/pdf/CEB0201.pdf> Acesso em: 01 ago. 2016.

. Ministério da Educação e do Desporto. Secretaria de Educação Especial. Política Nacional de Educação Especial na Perspectiva da Educação Inclusiva. Documento elaborado pelo Grupo de Trabalho nomeado pela Portaria Ministerial $n^{\circ} 555$, de 5 de junho de 2007, prorrogada pela Portaria $n^{\circ}$ 948, de 09/10/2007. Disponível em:

<http://peei.mec.gov.br/arquivos/politica_nacional_educacao_especial.pdf> Acesso em: 01 mar. 2017.

CARAPETIS J.R., STEER, A.C., MULHOLLAND E.K., et al. The global burden of group A streptococcal diseases. Lancet Infectious Diseases, v. 5, p. 685-94, 2005. Disponível em:

<http://www.ncbi.nlm.nih.gov/pubmed/16253886>Acesso em: 01 ago. 2016.

CAREGNATO, R.C.A., MUTTI, R. Pesquisa qualitativa: análise de discurso versus análise de conteúdo. Texto \& Contexto Enfermagem. v. 15, n.4, p. 679-84, 2006. Disponível em:

<http://www.scielo.br/pdf/tce/v15n4/v15n4a17> Acesso em: 20 dez. 2016. 


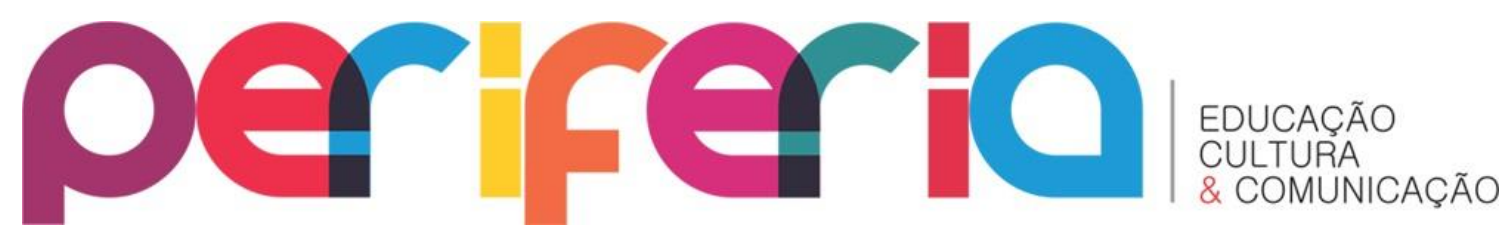

CECCIM, R. B. Criança hospitalizada: a atenção integral como uma escuta à vida. In: CECCIM, R. B.; CARVALHO, P. R. A. Criança hospitalizada: atenção integral como uma escuta à vida. Porto Alegre: Editora da Universidade/UFRGS, 1997.

FERREIRA, A.B.H. Miniaurélio Século XXI: 0 minidicionário da língua Portuguesa. $4^{\mathrm{a}}$ ed. Rio de Janeiro: Nova Fronteira, 2001.

FISCHER, R. M. B. Foucault e a análise do discurso em educação. Cadernos de Pesquisa, v. 9, n. 114, p. 197-223, 2001. Disponível em:

<http://www.scielo.br/pdf/\%0D/cp/n114/a09n114.pdf > Acesso em: 20 jun. 2017.

FONSECA, E.S. (org.). Atendimento Escolar Hospitalar: O Trabalho Pedagógico-Educacional no Ambiente Hospitalar. A Criança Doente Também Estuda e Aprende. Rio de Janeiro: UERJ, 2001

FONTES, R.S.; VASCONCELLOS, V.M.R. O papel da educação no hospital: uma reflexão com base nos estudos de Wallon e Vigotski. In: Caderno Cedes 73 - A educação da criança hospitalizada: as várias faces da pedagogia no contexto hospitalar. São Paulo: Cortez, 2007.

GLAT, R.; ANTUNES, K.C.V. A metodologia de história de vida na pesquisa em Educação Especial: a Escuta dos sujeitos. In: NUNES, L. R. d'O. P. Novas trilhas no modo de fazer pesquisa em educação especial. São Carlos: Marquezine \& Manzini: ABPEE, 2014

GLAT, R. BLANCO, L.M.V. Educação Especial no contexto de uma Educação Inclusiva. In: GLAT, R. Educação Inclusiva: Cultura e Cotidiano Escolar. Rio de Janeiro: 7Letras, 2007.

GLAT, R.; PLETSCH, M. D. O método de história de vida em pesquisas sobre auto-percepção de pessoas com necessidades educacionais especiais. Revista Educação Especial, v. 22, n. 34, p. 139-154, 2009. Disponível em: <http://www.ufsm.br/revistaeducacaoespecial> Acesso em 20 jun. 2017.

GIL, A.C. Métodos e técnicas de pesquisa social. 5ªed. São Paulo: Atlas, 1999.

LIMA, I.R.S. Políticas de educação escolar em ambientes hospitalares: em defesa da escola no hospital. Revista Educação e Políticas em Debate - v. 4, n.1, p. 29-53, 2015. Disponível em:

<http://www.seer.ufu.br/index.php/revistaeducaopoliticas/article/viewFile/ 31309/17043> Acesso em: 21 mai. 2017.

MINAYO, M.C.S. O Desafio do Conhecimento - Pesquisa Qualitativa em Saúde. Rio de Janeiro: HUCITEC-ABRASCO,1999. 


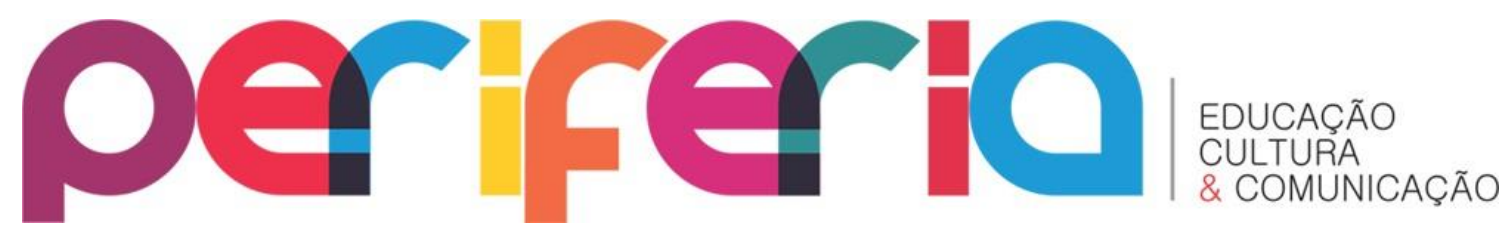

MULLER, R.E. Cardiopatia reumática com lesão valvar em crianças e adolescentes: fatores associados ao tempo até a terapêutica cirúrgica. Tese de Doutorado (Saúde da Criança e da Mulher), Instituto Fernandes Figueira/ FIOCRUZ: Rio de Janeiro, 2011.

NASCIMENTO, F.F. CAETANO, M.C. MULLER, R.E. et al. O trabalho pedagógico com pacientes de febre reumática e cardiopatias: uma experiência no Instituto Nacional de cardiologia. Adolescência \& Saúde - HUPE/UERJ, v. 1 n. 1, p. 25-29. Disponível em:

<http://www.adolescenciaesaude.com/detalhe_artigo.asp?id=27> Acesso em: 01 mai. 2017.

SCHILKE, A.L.T. O Fazer Pedagógico no Ambiente Hospitalar: Uma Possível Escuta das Potencialidades da Criança Internada, Monografia (Especialização em Alfabetização das Crianças das Classes Populares), Faculdade de Educação da Universidade Federal Fluminense, Niterói: UFF, 2003

TERRERI, M.T., LEN C., HILÁRIO, M. O. E., GOLDENBERG, J., et al. Utilização de recursos e custos de pacientes com febre reumática. Revista Brasileira de Reumatologia, v. 42, n. 4, p. 211-17, 2002.

WHO Expert Consultation on Rheumatic Fever and Rheumatic Heart Disease Rheumatic fever and rheumatic heart disease: report of a WHO Expert Consultation, Geneva: Switzerland, 2001. Disponível em: <http://www.who.int/cardiovascular_diseases/resources/en/cvd_trs923.pdf> Acesso em: 05 jan. 2017. 